\title{
Å opprette et fødselsregister i et utviklingsland - erfaringer fra Georgia
}

\author{
ORIGINALARTIKKEL

\section{ERIK EIK ANDA} \\ E-post: erik.anda@uit.no \\ Institutt for samfunnsmedisin \\ Det helsevitenskapelige fakultet \\ Universitetet i Troms $\emptyset$ - Norges arktiske universitet \\ Erik Eik Anda (f. 1973) er førsteamanuensis i epidemiologi og i global helse. \\ Forfatteren har fylt ut ICMJE-skjemaet og oppgir ingen interessekonflikter.
}

\section{INGVILD HERSOUG NEDBERG}

Institutt for samfunnsmedisin

Det helsevitenskapelige fakultet

Universitetet i Troms $\emptyset$ - Norges arktiske universitet

Ingvild Hersoug Nedberg (f. 1980) er forskningsstipendiat innen reproduktiv helse og epidemiologi. Forfatteren har fylt ut ICMJE-skjemaet og oppgir ingen interessekonflikter.

\section{CHARLOTTA RYLANDER}

Institutt for samfunnsmedisin

Det helsevitenskapelige fakultet

Universitetet i Troms $\emptyset$ - Norges arktiske universitet

Charlotta Rylander (f. 1978) er førsteamanuensis i epidemiologi og i ernæring.

Forfatteren har fylt ut ICMJE-skjemaet og oppgir ingen interessekonflikter.

\section{AMIRAN GAMKRELIDZE}

National Centre for Disease Control \& Public Health

Tbilisi, Georgia

Amiran Gamkrelidze (f. 1951) er generaldirektør for Georgias nasjonale senter for sykdomskontroll og folkehelse.

Forfatteren har fylt ut ICMJE-skjemaet og oppgir ingen interessekonflikter.

\section{ALEXANDER TURDZILADZE}

National Centre for Disease Control \& Public Health

Tbilisi, Georgia

Alexander Turdziladze (f. 1973) er visedirektør for Georgias nasjonale senter for sykdomskontroll og folkehelse.

Forfatteren har fylt ut ICMJE-skjemaet og oppgir ingen interessekonflikter.

\section{FINN EGIL SKJELDESTAD}

Institutt for samfunnsmedisin

Det helsevitenskapelige fakultet

Universitetet i Troms $\emptyset$ - Norges arktiske universitet

Finn Egil Skjeldestad (f. 1950) er professor i epidemiologi og i reproduktiv helse. 


\section{TAMAR UGULAVA}

United Nations Children's Fund (UNICEF)

Tbilisi, Georgia

Tamar Ugulava (f. 1966) er spesialist i mødre- og barnehelse.

Forfatteren har fylt ut ICMJE-skjemaet og oppgir ingen interessekonflikter.

\section{TORMOD BRENN}

Institutt for samfunnsmedisin

Det helsevitenskapelige fakultet

Universitetet i Troms $\varnothing$ - Norges arktiske universitet

Tormod Brenn (f. 1953) er førsteamanuensis i statistikk.

Forfatteren har fylt ut ICMJE-skjemaet og oppgir ingen interessekonflikter.

\section{BAKGRUNN}

Georgia er det første utviklingslandet i verden som har opprettet et digitalt medisinsk fødselsregister på nasjonalt nivå. Georgias fødselsregister ble offisielt åpnet 1. januar 2016. Hensikten med denne artikkelen er å vurdere kvaliteten på utvalgte variabler og presentere foreløpige resultater for 2016.

\section{MATERIALE OG METODE}

Registeret er strukturert på samme måte som de nordiske fødselsregistrene. Det er 285 medisinske institusjoner involvert, og disse registrerer 267 variabler fra og med uke 12 i svangerskapet frem til utskrivning fra sykehus. I 2016 ble 52399 kvinner og 53236 nyfødte registrert i Georgias fødselsregister.

\section{RESULTATER}

I 2016 var registerets dekningsgrad 93,9\%. Det var en forskjell på 3441 mellom antallet nyfødte som ble rapportert til registeret, og det antallet som fremkommer av offisiell statistikk. Gjennomsnittlig svangerskapsalder var 271,3 dager, og keisersnittsandelen var 43,5\%. Gjennomsnittlig fødselsvekt var 3262 gram. Barn som ble forløst med keisersnitt, hadde lavere gestasjonsalder og lavere fødselsvekt enn barn som ble forløst vaginalt.

\section{FORTOLKNING}

Hvert år blir det registrert flere nyfødte georgiske statsborgere enn det faktiske antallet fødsler i Georgia, og dette fører til unøyaktig offisiell rapportering av perinatal dødelighet.

Systematisk populasjonsbasert registrering av helserelaterte hendelser er avgjørende for å kunne utvikle verktøy som kan sette oss i stand til å forbedre helsevesenet og de enkelte helsetjenestene, og for å gi grunnlag for forskning.

I et fødselsregister står det oppført data om gravide kvinner, for eksempel demografiske data, sykdomshistorie, svangerskapskontroller og behandling under svangerskapet. Det blir også registrert data angående fødselen og det nyfødte barnet i en periode på opptil syv dager etter fødselen (1). Flere nordiske land etablerte fødselsregistre i epidemiologisk øyemed for ca. 50 år siden, for å gjøre det mulig å oppdage potensielle problemer på et tidligere tidspunkt, som thalidomid-katastrofen (2).

Nasjonale fødselsregistre utgjør en viktig del av helsevesenet i mange industriland. Det å innføre et fødselsregister krever en viss infrastruktur og økonomiske ressurser, noe som gjør at de sjelden prioriteres i mindre utviklede land.

Georgia er definert som et høyere mellominntektsland, og ble rangert som nummer 7o på 
indeksen for menneskelig utvikling i 2016. Republikken ligger i Kaukasus-regionen og hadde en anslått befolkning på ca. 3717100 i 2016 (3). I henhold til en folketelling i $2014 \mathrm{er}$ $86,4 \%$ av befolkningen definert som etnisk georgisk (4). Forventet levealder ved fødsel er 75 år, og $56,3 \%$ av befolkningen er bosatt i urbane områder (5). Georgias samlede fruktbarhetstall i 2015 var 2,3 (4). Dagens helsevesen ble innført i 2013 og tilbyr en universell svangerskapspakke. I tillegg gjør man bruk av privat helseforsikring og betaling av egenandel for eventuelle ekstra helsetjenester.

I Georgia er det gynekologer ved sykehus eller poliklinikker som yter all svangerskapsomsorg. Grunnleggende svangerskapsomsorg dekkes av staten, slik at dekningsgraden er høy (88,3\%) (3) og følger anbefalingene til Verdens helseorganisasjon, med minst fire kontroller per graviditet. I de nye anbefalingene anbefaler man åtte kontroller, og det er nå i ferd med å innføres (6).

Hele 99,5\% av alle gravide kvinner fødte i nærvær av kvalifisert personell ved en av landets 102 fødeavdelinger (3). Offisielt rapportert perinatal dødelighet (13,8/1 ooo) og mødredødelighet (36/10o ooo) (3) er høyere enn forventet i et land som er rangert så høyt som Georgia på indeksen for menneskelig utvikling, og der de fleste kvinner har tilstrekkelig tilgang til helsetjenester under graviditet og fødsel. Dette var grunnen til at Georgias helsemyndigheter i 2014 startet et samarbeid med UNICEF, Universitetet i Troms $\varnothing$ - Norges arktiske universitet og Georgias nasjonale senter for sykdomskontroll og folkehelse for å etablere et nasjonalt fødselsregister. Formålet var på sikt å kunne forbedre både mødrehelsen og den perinatale helsen.

Georgias fødselsregister ble åpnet 1. januar 2016 og er det første nasjonale fødselsregisteret som noen gang er blitt opprettet i et utviklingsland. Oppstartsmidlene kom fra UNICEF, mens Universitetet i Troms $\emptyset$ - Norges arktiske universitet og Georgias nasjonale senter for sykdomskontroll og folkehelse bidro med teknisk assistanse.

Målet med denne artikkelen er å vurdere kvaliteten på enkelte av registerets variabler og presentere foreløpige resultater fra det første årets drift (2016).

\section{Materiale og metode}

\section{GEORGIAS FØDSELSREGISTER}

Georgias statsborgere får alle tildelt et entydig 11-sifret personnummer, og fødselsregisteret gjør bruk av dette nummeret for å samordne registeret med data fra Justisdepartementets organ for tjenesteutvikling, som er Georgias folkeregister.

Et lokalt georgisk teknologiselskap (CiTi) utarbeidet hele registersystemet på 12 måneder, og de startet arbeidet i september 2014. Opplæring og utprøving fant sted høsten $2015 \mathrm{i}$ hovedstaden Tbilisi og i flere andre byer. Alle klinikker som tilbyr svangerskapsomsorg, fødselshjelp eller barselomsorg, har tilgang til internett, og data registreres elektronisk. Disse dataene blir oppdatert, eller nye data tilføyd, ved hver eneste konsultasjon i forbindelse med spontanaborter, svangerskapsavbrudd, svangerskapskontroller og fødsler.

Legene og jordmødrene ved de ulike helseinstitusjonene har ansvaret for å registrere informasjon for samtlige 267 variabler. Variablene inkluderer informasjon om mors sykdomshistorie og svangerskapshistorie, mor og fars levevaner, svangerskapet, fødselen og det nyfødte barnet. Enkelte variabler $(n=40)$ er påkrevde, f.eks. kvinnenes fødselsdato og estimerte blodtap, mens det er valgfritt å oppgi data for de øvrige variablene, for eksempel yrke eller grunnen til provosert abort. Helseinstitusjonene mottar tilbakebetaling fra myndighetene for hver enkelt kvinne som følger retningslinjene i det antenatale omsorgsprogrammet, men bare dersom fullgod informasjon blir oppført i registeret. Dette kravet ble gjort obligatorisk 1. mai 2016.

Registerkontoret, som er ansvarlig for kvalitetskontroll, har i dag fem heltidsansatte medarbeidere. Georgias fødselsregister genererer fødselsattester automatisk og kan lagre alle medisinske journaler på en integrert elektronisk plattform for e-helse. 


\section{DATABEHANDLING OG ETISKE HENSYN}

Georgias fødselsregister eies av staten Georgia. Universitetet i Troms $\emptyset$ - Norges arktiske universitet har innhentet tillatelse til å bruke registerets data i vitenskapelig øyemed, men har ikke overtatt noe slags eierskap. Alle personlige identifikatorer (navn og personnummer) i det gjeldende datasettet er blitt fjernet, og de enkelte sifrene i personnummeret er blitt skiftet ut med tilfeldig genererte tall. Identifikasjonsnøkkelen er blitt fjernet. Regional komité for medisinsk og helsefaglig forskningsetikk (REK Nord) har godkjent bruken av dataene (2017/404/REK Nord).

\section{STUDIENS UTVALG OG VARIABLER}

Det endelige utvalget besto av 53236 nyfødte barn og 52399 kvinner. Figur 1 viser hvilke eksklusjonskriterier som ble brukt.

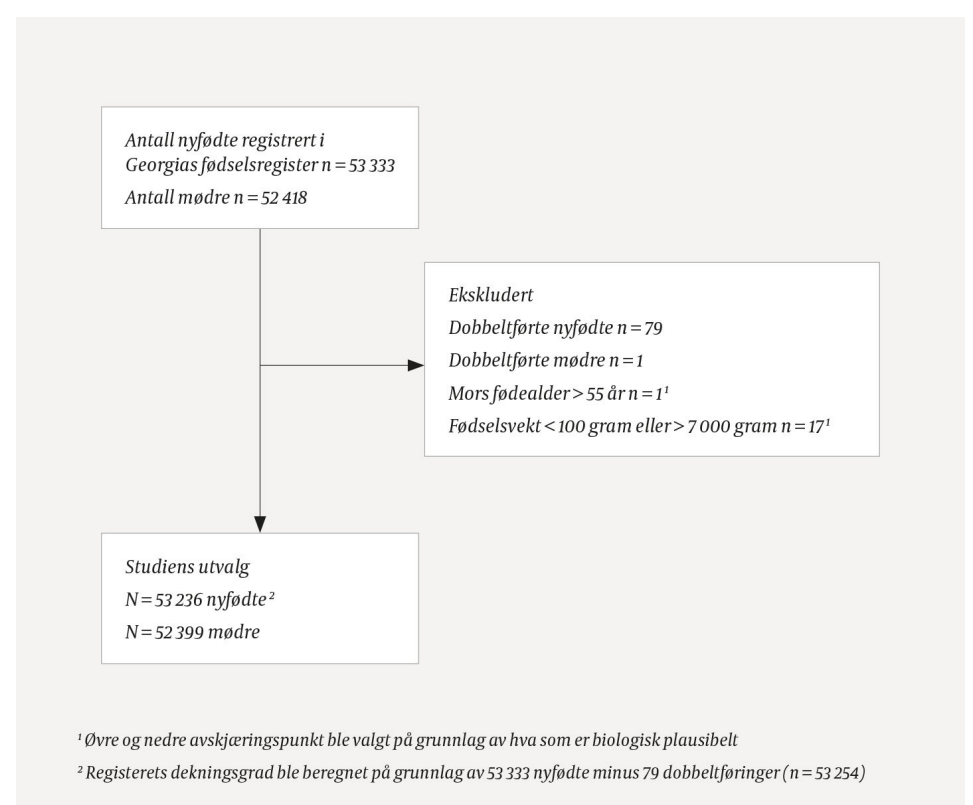

Figur 1 Flytdiagram som viser eksklusjonskriteriene for den analytiske delen av studien

Informasjon om mors alder, antall fødsler, forholdet mellom enkeltfødsler og flerfødsler, forløsningsmetode, svangerskapsalder, barnets fødselsvekt og kjønn ble hentet ut fra fødselsregisteret. Paritet ble ikke inkludert på grunn av betydelig mangel på data.

Fødselsregisterets dekningsgrad ble anslått ved å sammenligne antallet nyfødte som sto oppført i fødselsregisteret, med antallet nyfødte som sto oppført i folkeregisteret. Manglende informasjon ble beregnet, og det ble forventet $100 \%$ representativitet for alle variabler, for hver enkelt kvinne og hvert enkelt barn.

Svangerskapsalder blir primært rapportert på grunnlag av siste menstruasjon, hvis datoen er kjent, og sekundært på grunnlag av ultralyd. Den perinatale dødeligheten ble beregnet som antallet dødfødsler pluss antallet levendefødte barn som døde innen syv hele døgn/totalt antall nyfødte barn. Antallet perinatale dødsfall ble hentet fra Helsedepartementets data og den medisinske avdelingen ved det nasjonale senteret for sykdomskontroll og folkehelse. Dette var fordi dødsfall som inntraff etter utskrivning fra sykehus ikke ble registrert i Georgias fødselsregister på dette tidspunktet.

\section{STATISTISK ANALYSE}

Deskriptiv statistikk av kontinuerlige variabler presenteres som gjennomsnittstall med standardavvik. Kategoriske variabler presenteres ved hyppighet og prosentpoeng. Data for mor og barn presenteres i form av rapportert eller manglende svangerskapsalder og forløsningsmetode. Vi brukte statistikkprogrammet R (R Foundation for Statistical Computing, Wien, Østerrike), versjon 3.4.0, for å utarbeide de statistiske analysene. 


\section{RESULTATER}

Totalt ble 56695 fødsler innrapportert til Georgias folkeregister i 2016, mens det totale antallet som ble registrert i landets fødselsregister, var 53254 (fig 1). Fødselsregisterets dekningsgrad var derfor 93,9\%.

Den prosentvise mangelen på informasjon for de ulike variablene som presenteres i tabell 1, var som følger: mors alder (o \%), barnets kjønn (o,4\%), svangerskapsalder som antall dager (28\%) og fødselsvekt (o,4\%). Det var en betydelig andel manglende verdier for svangerskapsuke (27\%), og vi viser derfor kjennetegn ved mødre og nyfødte (etter både rapportert og manglende svangerskapsalder) i tabell 1, for å være sikre på at de to gruppene er sammenlignbare. I de tilfellene der det manglet informasjon om svangerskapsalder, var det mer sannsynlig at barnet ble forløst vaginalt og hadde litt høyere fødselsvekt enn barn med kjent svangerskapsalder (tab 1). Siden det ikke forelå noen indikasjon på lavere vekt blant barn med manglende verdi for svangerskapsalder anvendte vi de samme eksklusjonskriteriene for alle nyfødte barn (fig 1).

\section{Tabell 1}

Dataverdier for mødre og nyfødte med henholdsvis rapportert og manglende svangerskapsalder fra Georgias fødselsregister i 2016

\begin{tabular}{|c|c|c|}
\hline & $\begin{array}{c}\text { Rapportert } \\
\text { svangerskapsalder }\end{array}$ & $\begin{array}{c}\text { Manglende } \\
\text { svangerskapsalder }\end{array}$ \\
\hline \multicolumn{3}{|l|}{ Mødre } \\
\hline Totalt antall fødekvinner, $\mathrm{n}$ & 38270 & 14153 \\
\hline \multicolumn{3}{|l|}{ Flerfødsler, \% } \\
\hline Nei & 98,5 & 98,1 \\
\hline Ja & 1,5 & 1,9 \\
\hline \multicolumn{3}{|l|}{ Forløsningsmetode, \% } \\
\hline Vaginalt & 55,7 & 60,1 \\
\hline Keisersnitt & 44,3 & 39,9 \\
\hline $\begin{array}{l}\text { Mors alder (år)', gjennomsnitt } \\
\text { (standardavvik) }\end{array}$ & $27,1(5,8)$ & $27,4(5,8)$ \\
\hline \multicolumn{3}{|l|}{ Mors alder ${ }^{1}$ (år), \% } \\
\hline$<13-19$ & 0,2 & 8,0 \\
\hline $20-24$ & 28,3 & 26,5 \\
\hline $25-29$ & 31,2 & 31,1 \\
\hline $30-34$ & 20,5 & 21,6 \\
\hline $35-39$ & 9,6 & 10,2 \\
\hline $40-44$ & 2,3 & 2,3 \\
\hline$>45$ & 0,2 & 0,2 \\
\hline \multicolumn{3}{|l|}{ Nyfødte } \\
\hline Totalt antall nyfødte barn, n & 38839 & 14397 \\
\hline \multicolumn{3}{|l|}{ Flerfødsler, \% } \\
\hline Nei & 97,0 & 96,5 \\
\hline $\mathrm{Ja}$ & 3,0 & 3,6 \\
\hline \multicolumn{3}{|l|}{ Forløsningsmetode, $\%$} \\
\hline Vaginalt & 55,3 & 59,8 \\
\hline Keisersnitt & 44,7 & 40,2 \\
\hline \multicolumn{3}{|l|}{ Kjønn, \% } \\
\hline Gutter & 51,1 & 51,0 \\
\hline Jenter & 48,8 & 48,9 \\
\hline Ubestemt & 0,1 & 0,1 \\
\hline \multicolumn{3}{|l|}{$\begin{array}{l}\text { Fødselsvekt }{ }^{2} \text { (gram), gjennomsnitt } \\
\text { (standardavvik) }\end{array}$} \\
\hline Totalt & $3255(610)$ & 3281 (592) \\
\hline
\end{tabular}




\begin{tabular}{|c|c|c|}
\hline & $\begin{array}{c}\text { Rapportert } \\
\text { svangerskapsalder }\end{array}$ & $\begin{array}{c}\text { Manglende } \\
\text { svangerskapsalder }\end{array}$ \\
\hline \multicolumn{3}{|l|}{ Mødre } \\
\hline Gutter & 3319 (622) & $3329(602)$ \\
\hline Jenter & 3190 (587) & 3233 (574) \\
\hline \multicolumn{3}{|l|}{ Fødselsvekt ${ }^{2}$ (gram), \% } \\
\hline$<1000$ & 0,8 & 0,7 \\
\hline $1000-1499$ & 0,8 & 0,6 \\
\hline $1500-2499$ & 5,6 & 4,9 \\
\hline $2500-4499$ & 91,4 & 92,5 \\
\hline $4500-7000$ & 1,3 & 1,3 \\
\hline
\end{tabular}

${ }^{1}$ Antall manglende observasjoner: 159 med rapportert svangerskapsalder og 37 med manglende svangerskapsalder

${ }^{2}$ Antall manglende observasjoner: 99 med rapportert svangerskapsalder og 127 med manglende svangerskapsalder

Mors gjennomsnittlige alder var 27,2 år (standardavvik 5,8). Totalt var det 51568 enkeltfødsler og 1668 flerfødsler. Keisersnittsandelen var $43,5 \%$ av totalt antall fødsler. Av de 53236 nyfødte barna var 51,4\% gutter og 49,6\% jenter. Det ble registrert 742 perinatale dødsfall i 2016, og den perinatale dødeligheten var derfor 14,8/1 ooo nyfødte. Dødfødsler utgjorde 10,5/1 ooo av total perinatal dødelighet. Gjennomsnittlig svangerskapsalder var 271,3 dager (standardavvik 14,2). Nyfødte gutter hadde høyere fødselsvekt enn jenter, henholdsvis 3322 gram (standardavvik 617) og 3202 gram (standardavvik 583).

Barn som ble forløst med keisersnitt, hadde lavere svangerskapsalder enn de som ble forløst vaginalt (tab 2): 269,1 dager (standardavvik 13,0) sammenlignet med 273,2 (14,9) dager, og lavere fødselsvekt 3233 gram (standardavvik 625) sammenlignet med 3284 gram (standardavvik 588).

\section{Tabell 2}

Dataverdier for mødre og nyfødte etter forløsningsmetode, fra Georgias fødselsregister 2016

\begin{tabular}{|c|c|c|c|c|}
\hline & $\begin{array}{c}\text { Vaginal } \\
\text { forløsning }\end{array}$ & $\begin{array}{l}\text { Manglende Keisersnitt Manglende } \\
\text { data }\end{array}$ & Totalt & $\begin{array}{l}\text { Manglende } \\
\text { data }\end{array}$ \\
\hline \multicolumn{5}{|l|}{ Mødre } \\
\hline $\begin{array}{l}\text { Totalt antall } \\
\text { fødekvinner }\end{array}$ & 29820 & 22579 & $\begin{array}{c}52 \\
399 \\
\end{array}$ & \\
\hline \multicolumn{5}{|l|}{ Flerfødsler, \% } \\
\hline Nei & 99,1 & 97,5 & 98,4 & \\
\hline $\mathrm{Ja}$ & 0,9 & 2,5 & 1,6 & \\
\hline $\begin{array}{l}\text { Mors alder (år), } \\
\text { gjennomsnitt } \\
\text { (standardavvik) }\end{array}$ & $\begin{array}{l}26,4 \\
(5,5)\end{array}$ & $28,3(6,0)$ & $\begin{array}{l}27,2 \\
(5,8)\end{array}$ & \\
\hline \multicolumn{5}{|c|}{ Mors alder (år), \% } \\
\hline$<19$ & 9,6 & 5,9 & 8,0 & \\
\hline $20-24$ & 30,9 & 23,7 & 27,8 & \\
\hline $25-29$ & 31,9 & 30,2 & 31,2 & \\
\hline $30-34$ & 19,0 & 23,1 & 20,8 & \\
\hline $35-39$ & 7,3 & 13,1 & 9,8 & \\
\hline $40-44$ & 1,3 & 3,6 & 2,3 & \\
\hline$>45$ & 0,0 & 0,3 & 0,2 & \\
\hline \multicolumn{5}{|l|}{ Nyfødte } \\
\hline Antall nyfødte & 30084 & 23152 & $\begin{array}{c}53 \\
236 \\
\end{array}$ & \\
\hline
\end{tabular}




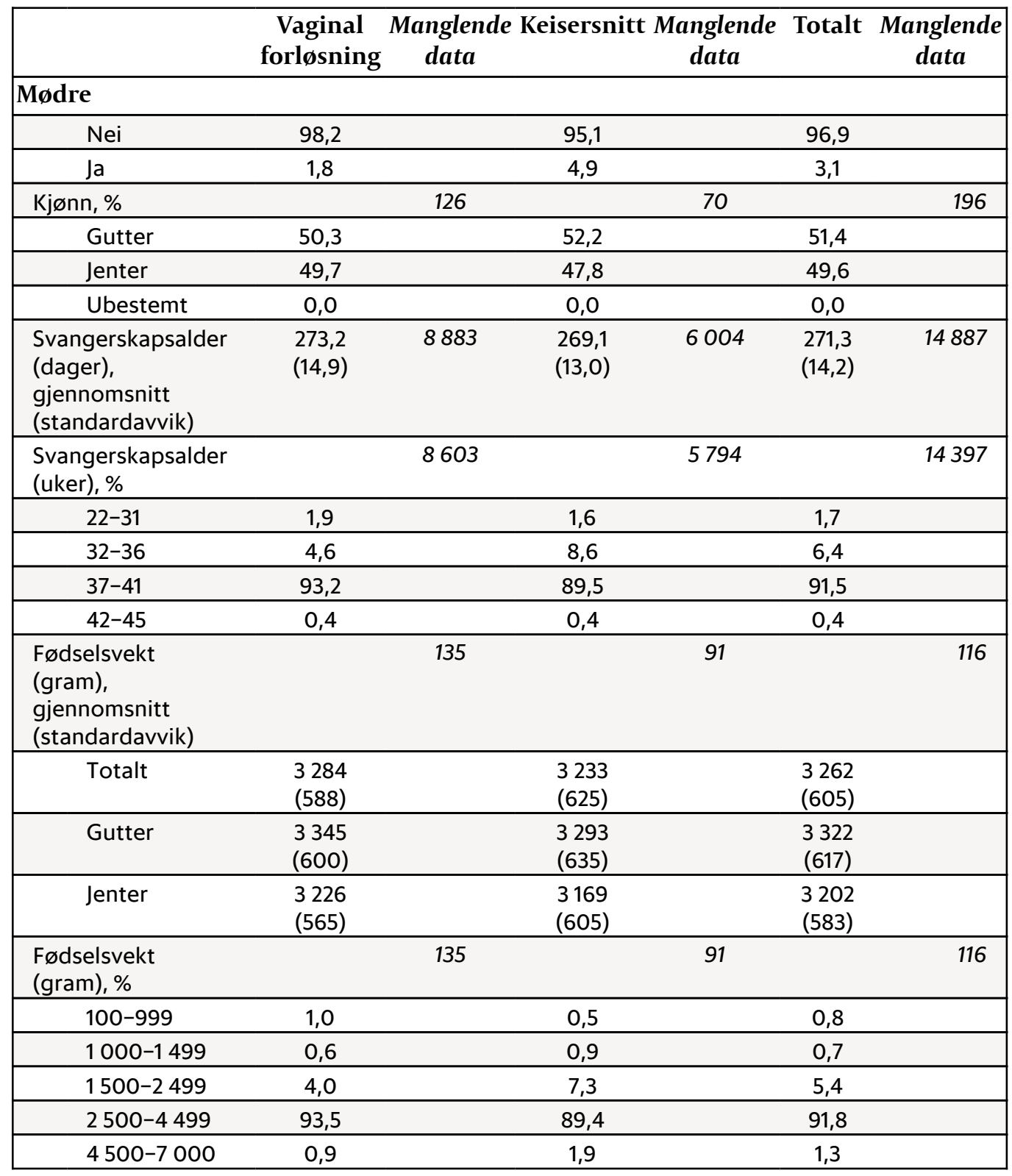

\section{DISKUSJON}

Resultatene våre viser at Georgias fødselsregister hadde en dekningsgrad på 93,9 \% i sitt første driftsår, sammenlignet med de offisielle tallene som ble innrapportert til Georgias folkeregister.

De første resultatene fra fødselsregisteret viser at den perinatale dødeligheten i Georgia i 2016 var 14,8/1 ooo, som er noe høyere enn den offisielle dødeligheten på 13,8/1 ooo (3). Det er sannsynlig at forklaringen på dette avviket ligger i at fødselsregisteret registrerer antallet barn som fødes i Georgia hvert år, med unntak av hjemmefødsler (- 0,5\%), mens folkeregisteret registrerer antallet nyfødte barn med georgisk statsborgerskap. Dette er en situasjon som gjerne kan inntreffe i land som ikke har et velfungerende fødselsregister.

Spedbarn kan etter loven registreres som georgiske statsborgere selv om de ikke er født i Georgia, så lenge én av foreldrene er georgisk statsborger (7). Foreldre velger gjerne å gjøre dette fordi det kan være fordelaktig, for eksempel kan georgiere besøke Schengen-området uten visum. Dette er en fordel som ingen av de tilstøtende landene har. Følgelig er det sannsynlig at den virkelige perinatale dødeligheten ligger mellom 13,8/1 ooo og 14,8/1 ooo, men nærmest det høyeste tallet.

Keisersnittsandelen i Georgia er 43,5\%, noe som er to til tre ganger høyere enn i Norden, der keisersnittsandelen varierer mellom 15 og 21 \% (8). Selv om Verdens helseorganisasjon ikke lenger anbefaler en bestemt keisersnittsandel, vil ikke andeler over $10 \%$ være forbundet med en reduksjon i mødredødeligheten og perinatal dødelighet (9). Den høye 
keisersnittsandelen er en utfordring for myndighetene, fordi keisersnitt er dyrere enn vaginal fødsel, men den høye andelen representerer også en byrde for kvinnene, fordi et keisersnitt predisponerer for forløsning med keisersnitt også ved senere fødsler (8).

Gjennomsnittlig svangerskapsalder i Georgia er 271 dager, noe som er fire dager kortere enn for eksempel i Norge (10). Det er mye mer sannsynlig at barn blir forløst med keisersnitt i Georgia (der gjennomsnittlig svangerskapsalder i keisersnittgruppen bare var 269 dager) enn i Norge, der keisersnittsandelen på 16,1 i 2016 (11). Hvis alle andre faktorer hadde vært like de to landene imellom, ville disse forskjellene kunnet tilsi at det foreligger en sammenheng mellom en høy keisersnittsandel og lavere svangerskapsalder. Dessverre har vi begrenset mulighet til å kunne hevde dette, både på grunn av studiens tverrsnittdesign og vår manglende tilgang på pålitelige data om klinisk indikasjon for å utføre keisersnitt i Georgia.

Resultatene våre understreker imidlertid at det er behov for å arbeide videre med å finne årsakene til, og konsekvensene av, den høye keisersnittsandelen i Georgia.

Dataene i Georgias fødselsregister er av akseptabel kvalitet og samsvarer med veletablerte internasjonale funn: Andelen guttebarn er noe høyere enn andelen jentebarn (12), fødselsvekten blant guttebarn er høyere sammenlignet med jentebarn (13), og $7 \%$ av de nyfødte barna hadde fødselsvekt $<2500$ gram (14). Registerets ansatte utfører løpende kvalitetskontroll av data som registreres. I tillegg inneholder systemet flere hundre innebygde kvalitetssikringsfunksjoner, for eksempel akseptabel variasjonsbredde for verdier.

Georgias fødselsregister har bare vært i drift i ett år, og svakheter ved systemet er forventet. Sykehus har meldt at noen ansatte mangler motivasjon til å rapportere informasjon til fødselsregisteret fordi dette blir betraktet som tilleggsarbeid som verken gagner dem selv eller pasientene. Det er derfor et betydelig antall manglende verdier for noen av de valgfrie variablene, for eksempel paritet og antall fostre. Variabelen for fødselsvekt var dessuten inkonsistent, idet et uforholdsmessig antall fødselsvekter var blitt avrundet til nærmeste hundre gram. Ideelt sett burde man bruke Wilcox og Russells metode (eller en tilpasset versjon) (15) for å dobbeltsjekke for sannsynlig fødselsvekt på rutinemessig basis. Georgias fødselsregister innførte flere omfattende oppgraderinger i løpet av mai og juni 2017 og vil også inkludere Wilcox og Russells metode så snart det foreligger et tilstrekkelig tallgrunnlag.

I løpet av utviklingsperioden oppdaget vi hvor viktig det er å sikre nasjonalt eierskap av det endelige produktet. Georgias fødselsregister har dessuten vært avhengig av et nasjonalt og institusjonelt initiativ som sporet til entusiasme og engasjement blant lokale og nasjonale helsemyndigheter som gjør bruk av registeret til å utarbeide statistikker og innføre kvalitetsforbedringer. Alt dette er forutsetninger for at et system som Georgias fødselsregister skal kunne være bærekraftig, noe som finner solid støtte i serien «Civil registration and vital statistics» som ble publisert i The Lancet i 2015 (16).

\section{Konklusjon}

I sitt første driftsår oppnådde Georgias fødselsregister en dekningsgrad på 93,9\% av totalt antall nyfødte barn. Utvalgte kjernevariabler viser et rimelig sammenfall med eksisterende kunnskap, men det er likevel behov for forbedring med hensyn til enkelte viktige indikatorer, for eksempel paritet og svangerskapsalder. Det er behov for fokus på den perinatale dødeligheten, som er høyere enn tidligere rapportert, og på den høye keisersnittsandelen. 
Georgia, er underestimerte

Keisersnittsandelen i Georgia i 2016 var 43,5\%, som er betydelig høyere enn det som er anbefalt for å redusere dødeligheten og sykeligheten

Både fødselsvekt og svangerskapsalder var lavere i gruppen som ble forløst med keisersnitt

\section{LITTERATUR:}

1. Gissler M, Louhiala P, Hemminki E. Nordic medical birth registers in epidemiological research. Eur J Epidemiol 1997; 13: 169-75. [PubMed][CrossRef]

2. Folkehelseinstituttet. Medisinsk fødselsregister - Historiske røtter.

https://www.fhi.no/hn/helseregistre-og-registre/mfr/medisinsk-fodselsregister-historis/(14.6.2017).

3. Gamkrelidze A, Kereselidze M, Tsintsadze M et al. Health care - statistical yearbook 2015-Georgia. Tbilisi: National centre for disease control and public health, 2016.

4. National Statistics Office of Georgia. Statistical yearbook of Georgia. Tbilisi: National Statistics Office of Georgia, 2016.

5. United Nations. Human Development Reports - Georgia: United Nations Development Programme 2016. http://hdr.undp.org/en/countries/profiles/GEO (7.6.2017).

6. World Health Organization. New guidelines on antenatal care for a positive pregnancy experience. http://www.who.int/reproductivehealth/news/antenatal-care/en/ (7.6.2017).

7. State Commission on Migration Issues. Acquisition of georgian citizenship. http://migration.commission.ge/index.php?article_id=165\&clang=1 (14.6.2017).

8. Pyykönen A, Gissler M, Løkkegaard E et al. Cesarean section trends in the Nordic Countries - a comparative analysis with the Robson classification. Acta Obstet Gynecol Scand 2017; 96: 607-16. [PubMed][CrossRef]

9. World Health Organization. WHO Statement on caesarean section rates. http://apps.who.int/iris/bitstream/10665/161442/1/WHO_RHR_15.02_eng.pdf?ua=1 (7.6.2017).

10. Folkehelseinstituttet. Medisinsk fødselsregister (MFR) og Abortregisteret. Standardstatistikk. F6: Svangerskapsvarighet: 2016. Folkehelseinstituttet 2017. http://statistikk.fhi.no/mfr/ (30.10.2017).

11. Folkehelseinstituttet. Medisinsk fødselsregister (MFR) og Abortregisteret. Standardstatistikk. F10c-2: Keisersnitt utført. Folkehelseinstituttet 2017. http://statistikk.fhi.no/mfr/ (30.10.2017).

12. Campbell RB. John Graunt, John Arbuthnott, and the human sex ratio. Hum Biol 2001; 73: 605-10. [PubMed][CrossRef]

13. Kramer MS. Determinants of low birth weight: methodological assessment and meta-analysis. Bull World Health Organ 1987; 65: 663-737. [PubMed]

14. United Nations Children's Fund. Low birthweight: Country, regional and global estimates. Report. New York, NY: Unicef, 2004.

15. Skjærven R, Gjessing HK, Bakketeig LS. Birthweight by gestational age in Norway. Acta Obstet Gynecol Scand 20oo; 79: 440-9. [PubMed][CrossRef]

16. AbouZahr C, de Savigny D, Mikkelsen L et al. Civil registration and vital statistics: progress in the data revolution for counting and accountability. Lancet 2015;386: 1373-85. [PubMed][CrossRef]

Publisert: 2. januar 2018. Tidsskr Nor Legeforen. DOI: 10.4045/tidsskr.17.0553

Mottatt 23.6.2017, første revisjon innsendt 12.10.2017, godkjent 2.11.2017.

(C) Tidsskrift for Den norske legeforening 2020. Lastet ned fra tidsskriftet.no 